\title{
The Vicious Combination of Left Ventricular Diastolic Dysfunction and Frailty
}

\author{
Tomoko Ishizu, MD, PhD
}

$\mathbf{T}$ The heart failure (HF) pandemic is an impeding problem in aging societies such as Japan. Thus, prevention of HF progression from stage A to stage $\mathrm{C}$ is the mandate issue to be solved. Left ventricular diastolic dysfunction is one of the major pathogeneses of $\mathrm{HF}$ with preserved ejection fraction (HFpEF) in the elderly population. In this issue of the Journal, Kusunose et $\mathrm{al}^{1}$ demonstrate a significant association between frailty and diastolic dysfunction, and both showed incremental prognostic significance in an elderly population with stage $\mathrm{A} / \mathrm{B} \mathrm{HF}$.

It is not hard to imagine that severe diastolic dysfunction causes shortness of breath on excursion, and patients tend to avoid exercise and prefer an inactive life style. Such a

\section{Article p2103}

sedentary daily activity habit may result in frailty with aging. On the other hand, it is unclear whether frailty itself affects the diastolic function of the left ventricle. Kusunose et $\mathrm{al}^{1}$ investigated the echocardiographic parameters and frailty in patients with LVEF $>45 \%$, non-atrial fibrillation, and non-significant valvular disease, and reported that the group of frail patients showed worse diastolic function compared with the other group without frailty. The results suggested a close relationship between frailty and diastolic function.

HFpEF patients have abnormalities in skeletal muscle

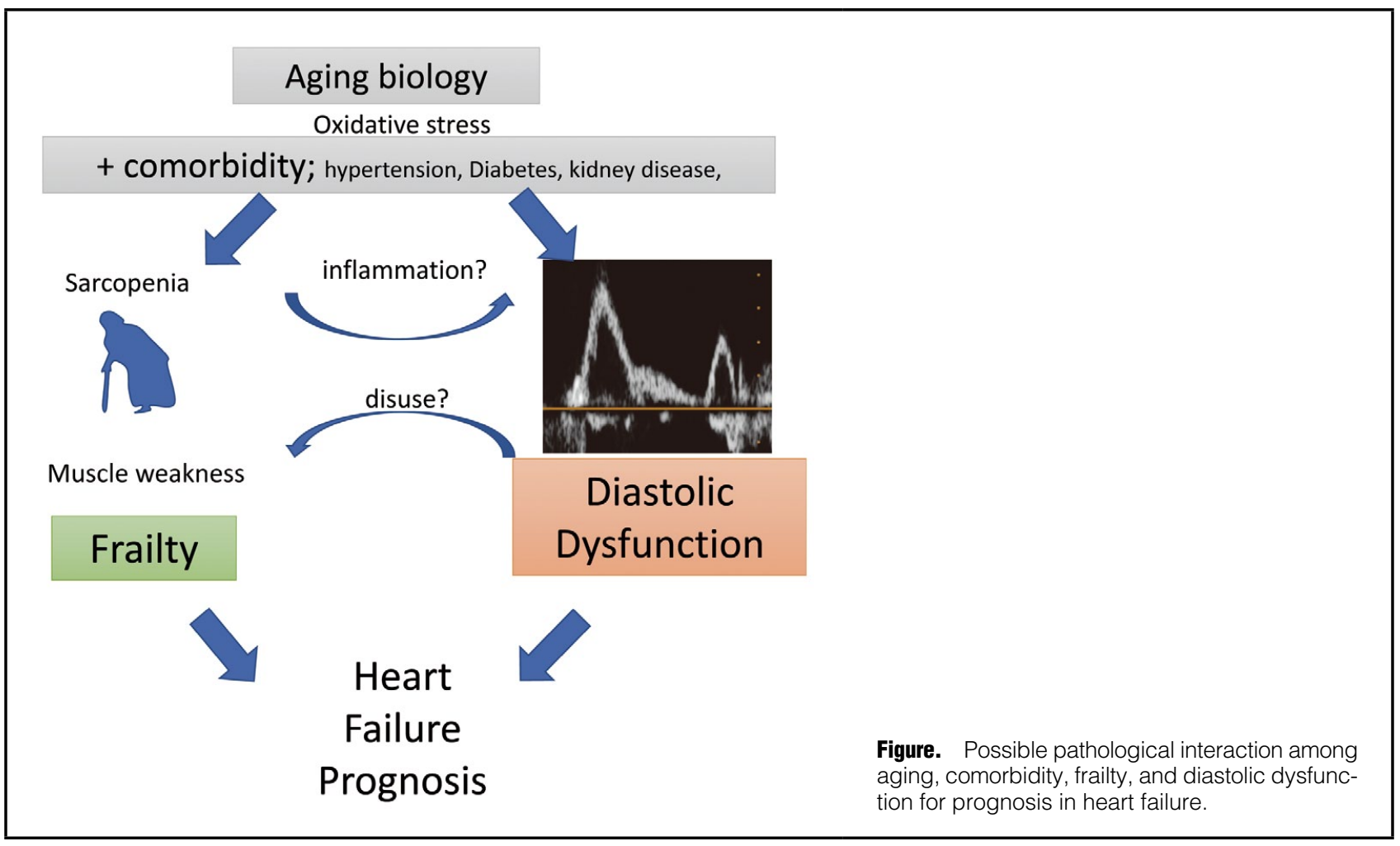

The opinions expressed in this article are not necessarily those of the editors or of the Japanese Circulation Society.

Received June 27, 2018; accepted June 28, 2018; released online July 13, 2018

Department of Clinical Laboratory Medicine, Faculty of Medicine, University of Tsukuba, Tsukuba, Japan

Mailing address: Tomoko Ishizu, MD, PhD, Department of Clinical Laboratory Medicine, Faculty of Medicine, University of

Tsukuba, 1-1-1 Tennodai, Tsukuba 305-8575, Japan. E-mail: tomoco@md.tsukuba.ac.jp

ISSN-1346-9843 All rights are reserved to the Japanese Circulation Society. For permissions, please e-mail: cj@j-circ.or.jp 
mass, ${ }^{2}$ composition, and oxidative metabolism. ${ }^{3}$ Why should certain HFpEF patients have accompanying muscle weakness? One possible answer is that HFpEF is a systemic disorder involving not only the cardiac muscles, but also skeletal muscle and that skeletal muscle and cardiac abnormalities are incited by common, circulating factors such as proinflammatory cytokines. ${ }^{4}$ Recently, systemic inflammation induced by sarcopenia, accompanied by frailty has been focused on as a pathogenesis of HFpEF evolution. ${ }^{5}$ Exercise training has been shown in multiple studies to significantly improve peak $\dot{\mathrm{VO}}_{2}$ in HFpEF. ${ }^{6}$ Therefore, rehabilitation for skeletal muscle strength may improve frailty and diastolic function but has not been examined systematically.

Another important message from the Kusunose et al presentation $^{\mathbf{1}}$ is that echocardiographic assessment of new diastolic dysfunction grade ${ }^{7,8}$ can predict HF prognosis significantly. "Diastology"9 was started in 1982 by Kitabatake et al reporting transmitral flow velocity pattern as a marker of diastolic function. The tissue Doppler velocity profile, focused on by Oki et al, or Nagueh et al, contributed to improving accuracy in assessing diastolic function by echocardiography. Recently, speckle tracking echocardiography-derived global longitudinal strain, ${ }^{10}$ as a new diagnostic echocardiographic modality to assess cardiac chamber deformation, may provide further improvement in assessing cardiac diastolic function and prognosis (Figure). Newly updated utilization of echocardiography must benefit the quality of daily clinical HF practice.

\section{References}

1. Kusunose K, Okushi Y, Yamada H, Nishio S, Torii Y, Hirata Y, et al. Prognostic value of frailty and diastolic dysfunction in elderly patients. Circ J 2018; 82: 2103-2110.

2. Haykowsky MJ, Brubaker PH, Morgan TM, Kritchevsky S, Eggebeen J, Kitzman DW. Impaired aerobic capacity and physical functional performance in older heart failure patients with preserved ejection fraction: Role of lean body mass. $J$ Gerontol A Biol Sci Med Sci 2013; 68: 968-975.

3. Bhella PS, Prasad A, Heinicke K, Hastings JL, Arbab-Zadeh A, Adams-Huet B, et al. Abnormal haemodynamic response to exercise in heart failure with preserved ejection fraction. Eur $J$ Heart Fail 2011; 13: 1296-1304.

4. Ather S, Chan W, Bozkurt B, Aguilar D, Ramasubbu K, Zachariah AA, et al. Impact of noncardiac comorbidities on morbidity and mortality in a predominantly male population with heart failure and preserved versus reduced ejection fraction. J Am Coll Cardiol 2012; 59: 998-1005.

5. Shah SJ, Kitzman DW, Borlaug BA, van Heerebeek L, Zile MR, Kass DA, et al. Phenotype-specific treatment of heart failure with preserved ejection fraction: A multiorgan roadmap. Circulation 2016; 134: 73-90.

6. Edelmann F, Gelbrich G, Dungen HD, Frohling S, Wachter R, Stahrenberg R, et al. Exercise training improves exercise capacity and diastolic function in patients with heart failure with preserved ejection fraction: Results of the Ex-DHF (Exercise training in Diastolic Heart Failure) pilot study. J Am Coll Cardiol 2011; 58: $1780-1791$.

7. Smiseth OA. Evaluation of left ventricular diastolic function: State of the art after 35 years with Doppler assessment. $J$ Echocardiogr 2018; 16: 55-64.

8. Nagueh SF, Smiseth OA, Appleton CP, Byrd BF 3rd, Dokainish $\mathrm{H}$, Edvardsen T, et al. Recommendations for the evaluation of left ventricular diastolic function by echocardiography: An Update from the American Society of Echocardiography and the European Association of Cardiovascular Imaging. $\mathrm{J}$ Am Soc Echocardiogr 2016; 29: 277-314.

9. Oki T, Miyoshi H, Oishi Y, Mizuguchi Y, Iuchi A, Yamada H, et al. Challenges for 'diastology': Contributions from Japanese researchers. J Echocardiogr 2016; 14: 93-103.

10. Dohi K, Sugiura E, Ito M. Utility of strain-echocardiography in current clinical practice. J Echocardiogr 2016; 14: 61-70. 